\title{
WATER STRESS AFFECTS THE GERMINATION, EMERGENCE AND GROWTH OF DIFFERENT SORGHUM CULTIVARS
}

\author{
Wondimu Bayu ${ }^{1}$, N.F.G. Rethman ${ }^{2}$, P.S. Hammes ${ }^{2}$, P.A. Pieterse ${ }^{2}$, J. Grimbeek ${ }^{3}$ and \\ M. Van Der Linde ${ }^{3}$ \\ 1 Sirinka Agricultural Research Center, PO Box 74, Weldia, Welo, Ethiopia \\ E-mail: wondimubayu@yahoo.com \\ 2 Department of Plant Production and Soil Science, University of Pretoria, Pretoria 0002, South Africa \\ ${ }^{3}$ Department of Statistics, University of Pretoria, Pretoria 0002, South Africa
}

\begin{abstract}
Two experiments were conducted to study the effects of water deficit stress on the germination, emergence and seedling growth of sorghum [Sorghum bicolor (L.) Moench] using Completely Randomised Block Design in four replications. Five sorghum cultivars (Jigurti, Gambella 1107, Meko, 76 T1 \#23 and P9403) were evaluated under three water deficit stress treatments $(0,-0.20$ and -0.85 MPa) using PEG as an osmoticum (Experiment I) and under four varying growing media water contents (100, 60, 40 and $20 \%$ of field capacity) using sand (Experiment II). In both experiments, water deficit stress significantly reduced the rate and percentage of germination and emergence and early seedlings growth. Coleoptile, mesocotyl, radicle, and seedling shoot and root lengths, as well as root area were adversely affected by water deficit stress. Cultivars differed in the rate and percentage of germination, and emergence and seedling growth. Gambella 1107, Meko and P9403 had significantly $(\mathrm{P}<0.01)$ higher rates and percentages of germination and emergence. The rate of germination and emergence, the growth of the coleoptile, mesocotyl, and radicle and the shoot and root length and root area were found important traits to identify cultivars tolerant to water deficit stress at germination.
\end{abstract}

Key words/phra ses: Emergence, germination, seedling growth, sorghum, water deficit

\section{INTRODUCTION}

A major constraint of dryland sorghum production, in the semi-arid regions is the lack of sufficient water in the seeding zone at planting. Semi-arid areas, such as those of northeastern Ethiopia, are characterized by high temperatures, high evaporative demands, and limited and erratic precipitation, resulting in rapid drying of the soil surrounding the seed thus affecting seed germination, emergence and then seedling es tablishment. Thus, water stress is an overriding environmental factor governing germination and seedling establishment and consequently crop production.

Water deficit stress tolerance during germination, emergence and early seedling growth are particularly important traits for a successful establishment of crop plants as these traits determine stand establishment and affect the final yield (Brigg and Aytenfisu, 1979). Despite the fact that germination and seedling establishment are important traits for the early establishment of plants under water deficit stress conditions, most studies on water deficit stress tolerance have focused on the late vegetative and reproductive period of growth. Nonetheless, traits of water deficit stress tolerance should also include the ability of seeds to germinate, emerge and establish under limited moisture availability.

According to Belay and Beker (1996), germination, emergence and seedling growth under water deficit stress conditions vary among cultivars of tef. However, little is known about the extent of genetic differences in germination, emergence and seedling growth among different sorghum cultivars grown in Ethiopia under water deficit stress conditions. Therefore, these experiments were conducted to study the effect of water deficit stress on seed germination, emergence and seedling growth of sorghum and to evaluate cultivars differences to identify cultivars tolerant to drought for further agronomic and breeding importance.

\section{MATERIALS AND METHODS}

\section{Experiment I}

An experiment was conducted in the laboratory of the Department of Plant Production and Soil Science of the University of Pretoria. Five sorghum cultivars (Jigurti, Gambella 1107, Meko, 76 T1 \#23 and P9403) from Ethiopia, were evaluated for germination under three water deficit stress levels, 
representing no stress $(0 \mathrm{MPa})$, mild stress $(-0.20$ $\mathrm{MPa})$ and severe stress $(-0.85 \mathrm{MPa})$. These water deficit treatments were based on the results from a preliminary trial. Seeds were placed in petri dishes, $9 \mathrm{~cm}$ in diameter, lined with double layer Whatman No. 3 filter paper disks. The filter papers were moistened with $7 \mathrm{ml}$ of either pure water or polyethylene glycol 6000 (PEG-6000) solutions of 10 or $20 \%(\mathrm{w} / \mathrm{v})$. The equivalent water potentials were $0,-0.20$ and $-0.85 \mathrm{MPa}$, respectively. Seeds were germinated in an incubator maintained at a constant temperature of $26^{\circ} \mathrm{C}$ in complete darkness, for five days.

The osmolality (C) of the PEG-6000 solutions was determined with a digital Micro-osmometer and converted from mOsmol $\mathrm{kg}^{-1}$ to MPa using Vant Hoff's equation:

$$
\text { ? }{ }_{\mathrm{s}}(\mathrm{MP} ?)=\mathrm{RTSCj}
$$

where

$\mathrm{R}$ is the gas constant $\left(8.314 \times 10^{-6} \mathrm{~m}^{3} \mathrm{MPa} \mathrm{mol}^{-1} \mathrm{~K}^{-1}\right)$,

$\mathrm{T}$ is temperature in Kelvin $\left({ }^{\circ} \mathrm{C}+273\right)$ and

$\mathrm{Cj}$ is Osmolality (concentration of particles in one litre of water).

The petri dishes were hermetically sealed with parafilm to prevent evaporation. The experiment was laid out in a completely randomised block design with four replications. The experimental layout was arranged in a factorial experiment with osmotic potential and cultivars as factors. Germination counts were made every 24 hours. Seeds with a radicle protrusion of $2 \mathrm{~mm}$ or greater were considered as germinated. After five days the lengths of radicles, coleoptiles and mesocotyls of 10 seedlings were measured. Mean time to final germination (MTG) was calculated according to Brar and Stewart (1994) from the formula:

$$
\operatorname{MTG}(\mathrm{d})=\mathrm{S}\left(\mathrm{n}^{*} \mathrm{~d}\right) / \mathrm{N}
$$

where

$\mathrm{n}$ is the number of seeds germinated between scoring intervals;

$\mathrm{d}$ is the incubation period in days at that time point and

$\mathrm{N}$ is the total number of seeds germinated in the treatment.

Average rates of germination (AGR, \% d $\mathrm{d}^{1}$ ) were calculated according to Emmerich and Hardegree (1990) from the formula:

where

$$
\operatorname{AGR}\left(\%, \mathrm{~d}^{-1}\right)=\mathrm{S}\left[\left(\mathrm{G}_{\mathrm{i}}-\mathrm{G}_{\mathrm{i}-1}\right) / \mathrm{i}\right]
$$

$i$ is the germination count day,

$\mathrm{G}_{\mathrm{i}}$ is the percentage of seeds germinated through Day i, and

$\mathrm{G}_{\mathrm{i}-1}$ is the percentage of seeds germinated through the previous count day.

\section{Experiment II}

Seedling emergence and growth of the five sorghum cultivars (Jigurti, Gambella 1107, Meko, 76 T1 \#23 and P9403) were studied in a pot experiment with four growing media water content levels [field capacity (100\% FC), $60 \%$ FC, $40 \%$ FC and 20\% FC]. Field capacity is the water content of the soil at which drainage rate is negligible after saturation. The experiment was conducted as a factorial experiment with growing media water content levels and cultivars as factors in a completely randomised block design with four replications. Water content at field capacity of airdried sand was determined by the gravimetric method. The four soil water content levels $(100 \%$, $60 \%, 40 \%$ and $20 \%$ FC) were achieved by adding $64,38,26$ and $13 \mathrm{ml}$ of water, respectively. The water was thoroughly mixed with $2 \mathrm{~kg}$ of air-dried sand using an electric mixer. The sand and water mixture was then placed in polyethylene bags in pots and left for three days to equilibrate. The bags were closed to avoid evaporation. Fifty seeds of each cultivar were planted in each pot. The pots were placed in a growth chamber adjusted to a constant temperature of $25^{\circ} \mathrm{C}$ and complete darkness until germinant emergence was detected. Immediately after germinant emergence the growth chamber was adjusted to a 12-hour photoperiod. Seedlings were grown in the growth chamber at $310 \mu \mathrm{mol} \mathrm{m} \mathrm{m}^{-2} \mathrm{~s}^{-1}$ photosynthetic radiation.

Germinant emergence was recorded for four days starting from the first observation of emergence. Four days after emergence, all but eight uniform seedlings were removed from each pot. Eleven days after emergence, shoot length of eight seedlings was measured and then seedlings were uprooted and the total root length and root area were measured by scanning the roots and analysing the image with a "GSRoot" analyser. From emergence data, the Emergence Index (Ie, \% $\mathrm{d}^{-1}$ ) was calculated using the formula of Brar et al. (1992) where:

$$
\text { Ie }\left(\% \mathrm{~d}^{-1}\right)=\mathrm{S} \text { ei } / \mathrm{di}
$$

where

ei is the cumulative number of seedlings emerged on day $i$, and

di is number of days from planting to day $i$.

In both experiments, data were ranked prior to analysis of variance to meet the requirements for ANOVA. Analysis of variance for the measured parameters was performed using the SAS statistical program (BAS V8.2, SAS Institute Inc., Cary, NC, USA). 


\section{RESULTS AND DISCUSSION}

\section{Experiment I}

\section{Rate and percentage of germination}

Significant $(\mathrm{P}<0.01)$ differences in final germination percentage were observed between water deficit treatments and between cultivars. The water deficit $x$ cultivars interactions were, however, non significant. The results of the main effects of water deficit stress treatments indicated significant $(\mathrm{P}<0.01)$ reduction in final germination percentage under severe water deficit stress $(-0.85 \mathrm{MPa})$ $(80.3 \%)$, while germination percentage under mild water deficit (-0.20 MPa) $(95.6 \%)$ was comparable to the control (0 MPa) (94.7\%) (Fig. 1a). The reduction in germination percentage is due to low seed water uptake. Reduction in water uptake impaires cell turgor and then cell division and elongation thereby inhibiting radicle protrusion (Gurmu and Naylor, 1991). According to Gardner et al. (1985) a less-than-optimum growing media water content usually results in partial imbibition, which often results to low cell turgor.

Percentage germination, averaged across water deficit stress treatments, differed between cultivars where Gambella 1107, Meko and $P 9403$ had the highest germination percentages, while $76 \mathrm{~T} 1$ \#23 had the lowest germination percentage (Fig. 1b).
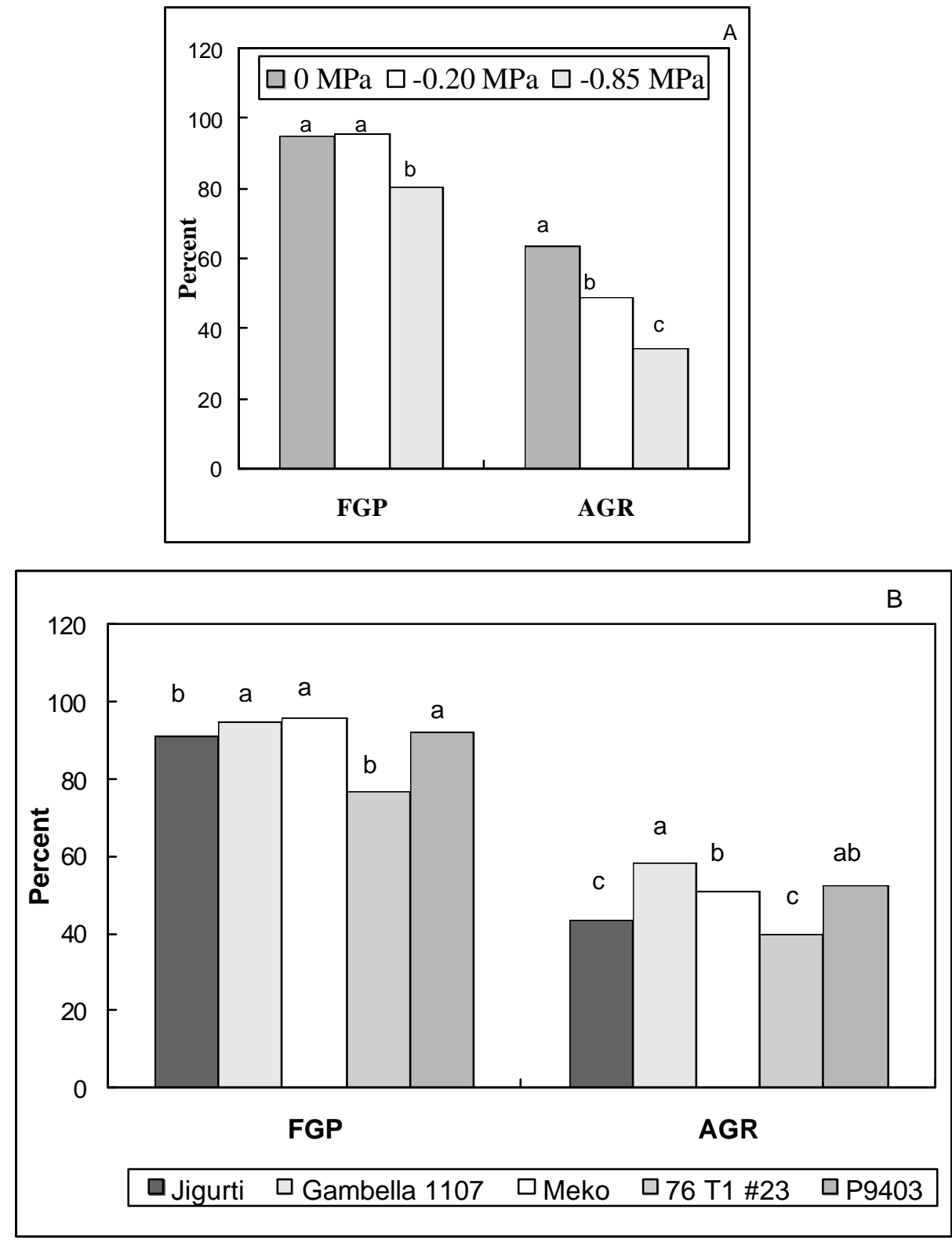

Figs $1 a$ and $b$. Effect of water deficit stress (A) and cultivar differences (B) on final germination percentage (FGP) and average germination rate (AGR). Means followed by the same letters for each parameter are not significantly different at $P \leq 0.05$. 
The rate of germination $\left(\begin{array}{lll}\% & \mathrm{~d}^{-1}\end{array}\right)$ differed significantly only among the main effects of water deficit treatments and among cultivars. The results indicated an increased reduction in the rate of germination as the water deficit stress level increased (Fig. 1a). The rate of germination was reduced by $23 \%$ under mild water deficit stress $(-0.20$ $\mathrm{MPa}$ ) and by nearly $50 \%$ under sever water deficit stress $(-0.85 \mathrm{MPa})$ conditions. Unlike germination percentage, the rate of germination was significantly affected by mild water deficit stress -0.20 $\mathrm{MPa}$ ) indicating that the rate of germination is more sensitive to mild water stress than germination percentage. This result is in agreement with that of Falleri (1994) who observed a greater effect of water deficit stress on the rate of germination than on germination percentage.

The results of cultivar differences in the rate of germination indicated that Gambella 1107, Meko and $\mathrm{P} 9403$ had significantly $(\mathrm{P}<0.01)$ higher rates of germination compared b Jigurti and 76 T1 \#23 (Fig. 1b). The rate of germination ranged from $58.2 \% \mathrm{~d}^{-1}$ for Gambella 1107 to $39.9 \% \mathrm{~d}^{-1}$ for $76 \mathrm{~T} 1$ \#23. Rapid germination permits the secondary root system to access wet soil ahead of the drying front in semi-arid environments (Baalbaki et al., 1999).

Significant $(\mathrm{P}<0.01)$ differences in mean germination time (MGT) were observed among the water deficit stress treatments and among cultivars. Averaged across cultivars, MGT increased as the water deficit stress level increased (Fig. 2a). Lafond and Baker (1986) also observed an increase in germination time in wheat as osmotic stress was increased. Sorghum cultivars differed in MGT with Gambella 1107, Meko and P9403 requiring a shorter time while Jigurti and $76 \mathrm{~T} 1$ \#23 requiring a longer time to reach final germination (Fig. 2b).

The percentage and rate of germination of crop seeds are of considerable agronomic importance. Reduction in the rate of germination due to water deficit would be particularly critical in semi-arid areas where moisture availability in the seed zone occurs for a brief period. Thus, one of the most important agronomic aspects of crop establishment is the rate at which a sufficient number of seeds germinate and establish a stand during the limited period when environmental conditions are suitable.

\section{Coleoptile, mesocotyl and radicle length}

Significant $(\mathrm{P}<0.01)$ differences in coleoptile length were observed between water deficit stress treatments and between cultivars. The water deficit $x$ cultivars interactions were not significant. Averaged across cultivars, coleoptile length progressively decreased with increasing water deficit stress (Fig. 3a). The length of the coleoptile was reduced by $34 \%$ under mild water deficit stress $(-020 \mathrm{MPa})$ and by $77 \%$ under severe water deficit stress $(-0.85 \mathrm{MPa})$ conditions, compared to the control $(0 \mathrm{MPa})$. Reduction in coleoptile length under water deficit stress is in accordance with the results of Lafond and Baker (1986) in wheat. The development of weak coleoptiles under water deficit stress implies poor opportunity for seedlings emergence and establishment.

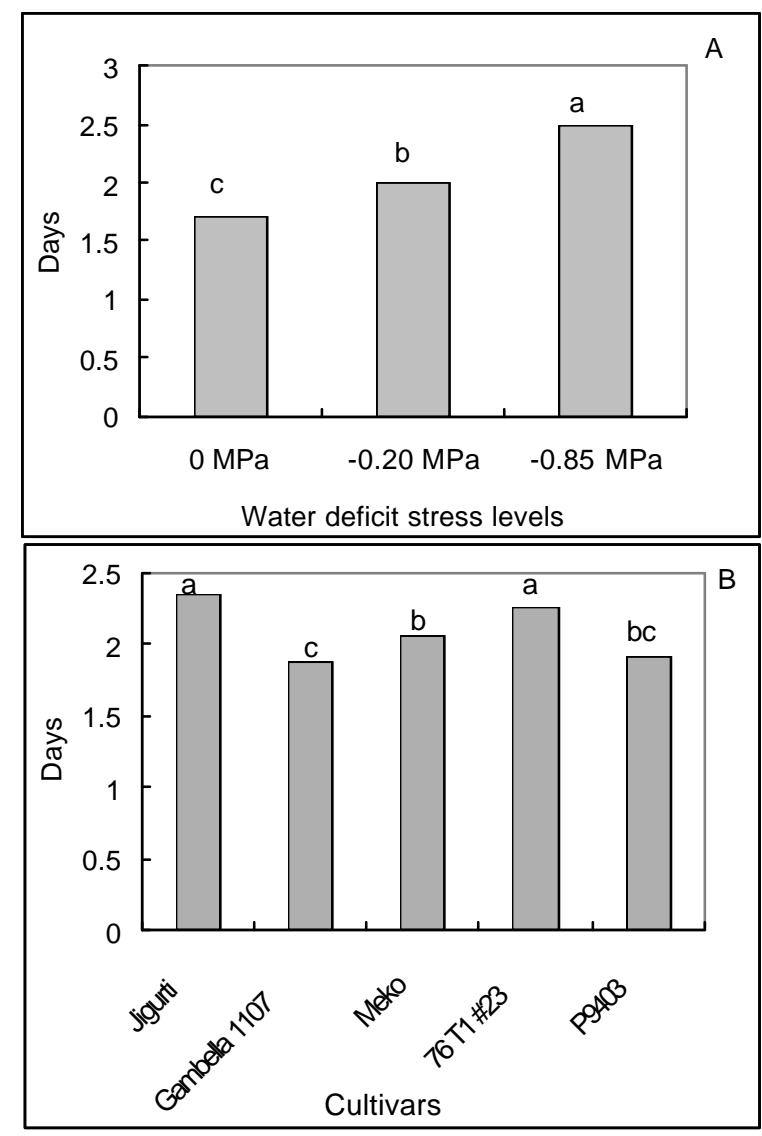

Figs $2 a$ and $b$. Effect of water deficit stress (A) and cultivar differences (B) on mean time to final germination. Bars followed by the same letters are not significantly different at $\mathrm{P} \leq 0.05$. 
Coleoptile length differences between cultivars were significant with Gambella 1107 having the longest coleoptile. The other four cultivars had comparable coleoptile lengths (Fig. 3b). The observed variability in sorghum cultivars with respect to coleoptile length is in agreement with the results of Wanjari and Bhoyar (1980).
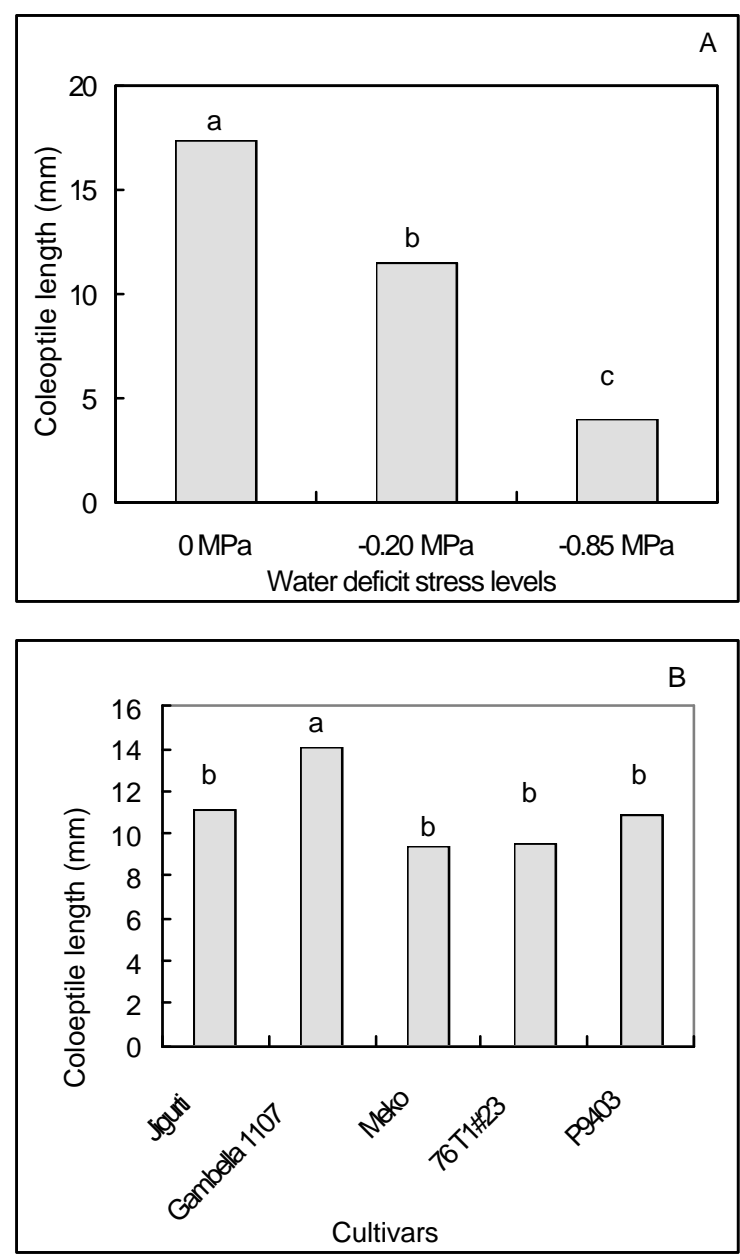

Figs $3 a$ and $b$. Effect of water deficit stress (A) and cultivar differences (B) on coleoptile length. Bars followed by the same letters are not significantly different at $\mathrm{P} \leq 0.05$.

Mesocotyl length differences between the interaction effects of water deficit stress and cultivars were significant (Fig. 4a). In all cultivars, mesocotyl length decreased as water deficit stress increased, but the extent of the decrease differed for each cultivar, with Gambella 1107 and P9403 having the least reductions $(27-70 \%$ and $13-67 \%$ respectively). Mesocotyl length decreased from 11$33 \mathrm{~mm}$ at $0 \mathrm{MPa}$ to $8-20$ and $2-6 \mathrm{~mm}$ at -0.20 and $0.85 \mathrm{MPa}$, respectively. This observation agrees with the reports of Takahashi (1978) who observed inhibited mesocotyl and coleoptile growth in rice under water deficit stress.

Cultivars Gambella 1107 and P9403, having longer coleoptiles and mesocotyls under water deficit stress, could have better potential for rapid emergence from the soil as sorghum seedlings emerge from the soil by elongating the mesocotyl and coleoptile. Coleoptile and mesocotyl elongation parameters are important traits in evaluating seed germination under water stress as rate and percentage of germination alone cannot assure seedling emergence (Takahashi, 1978). Thus, cultivar selection for water deficit stress tolerance during the germination stage should include coleoptile and mesocotyl elongation parameters.

Significant differences in radicle length were observed between the interaction effects of water deficit stress and cultivars (Fig. 4b). Radicle length in Jigurti, Gambella 1107 and 76 T1 \#23 decreased progressively as the level of water deficit stress increased. Whereas in Meko and $P 9403$ radicle length decreased significantly only under severe water deficit stress $(-0.85 \mathrm{MPa})$. Under mild $(-0.20$ $\mathrm{MPa})$ and severe $(-0.85 \mathrm{MPa})$ water deficit stress conditions, radicle length decreased by 17 to $52 \%$ for Jigurti, 16 to $46 \%$ for Gambella 1107, 3 to $47 \%$ for Meko, 18 to $63 \%$ for 76 T1 \#23 and 6 to $47 \%$ for P9403 relative to the control (0 MPa). Under mild water deficit condition only 76 T1 \#23 differed significantly from the rest of the cultivars. But under severe water deficit stress, more cultivar differences were observed where $76 \mathrm{~T} 1$ \#23 and Gambella 1107 developed significantly shorter and longer radicles respectively. According to Gurmu and Naylor (1991), inhibition of radicle emergence and growth under water deficit stress could be due to impairment of cell division and elongation resulting from a reduction in the turgor of the radicle cells. Gurmu and Naylor (1991) reported similar results where radicle elongation in sorghum and wheat was retarded under low water potential. 

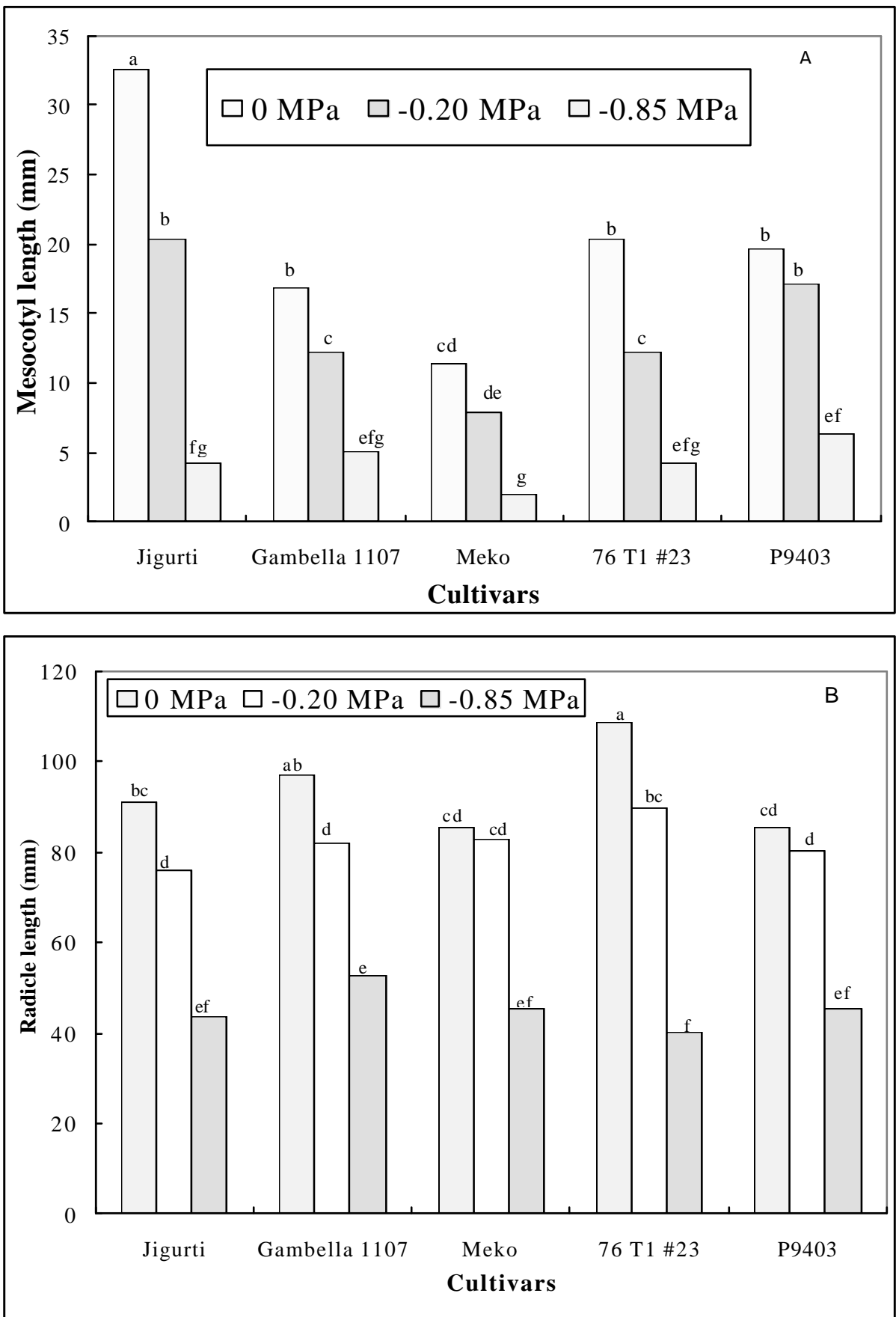

Figs $4 a$ and b. Effect of water deficit stress on the mesocotyl (A) and radicle (B) lengths of sorghum cultivars. Bars followed by the same letters are not significantly different at $\mathrm{P} \leq 0.05$.

\section{Experiment II}

Rate and percentage of seedling emergence

Significant $(\mathrm{P}<0.01)$ differences in percentage seedling emergence were observed between the water content $x$ cultivar interaction effects. No plants emerged in the $20 \%$ FC treatment and this treatment is excluded from the discussion. The results indicate that for all cultivars, except Jigurti and P9403, emergence started declining at $40 \% \mathrm{FC}$, while in Jigurti and $\mathrm{P} 9403$ it started declining at $60 \%$ FC (Fig. 5a). At 60\% FC Gambella 1107, Meko and P9403 and at 40\% FC Gambella 1107 and P9403 registered significantly higher percentage emergence than Jigurti and 76 T1 \#23. The better emergence in Gambella 1107 and P9403 in this experiment agrees with the observation in 
Experiment I where these two cultivars developed longer coleoptiles and mesocotyls. Compared to emergence at field capacity (100\% FC), Jigurti (21 and 34\%) and 76 T1 \#23 (6 and 35\%) had the highest reduction in emergence at 60 and $40 \%$ FC. Gambella 1107 (3 and 8\%) and P9403 (6 and 15\%) were the least affected. According to Brar et al. (1992), the reduction in seedling emergence at low growing media water content possibly resulted from a low seed-water contact. This is apparently because the water is adsorbed on the surface of the soil particles with a force greater than the absorbing capacity of the seed. Furthermore, at low water contents the rate of soil moisture movement is too slow to supply sufficient water to the immediate environment of the seed for its germination (Hunter and Erickson, 1952). Emergence index $\left(\% \mathrm{day}^{-1}\right)$, a parameter indicating the rate of emergence, decreased following the decrease in growing media water content (Fig. 5b). Gambella 1107, Meko and P9403 had the highest and Jigurti and $76 \mathrm{~T} 1 \# 23$ the lowest rates of emergence at all growing media water content treatments. These cultivars had similar performance in the PEG experiment for the rate of germination.
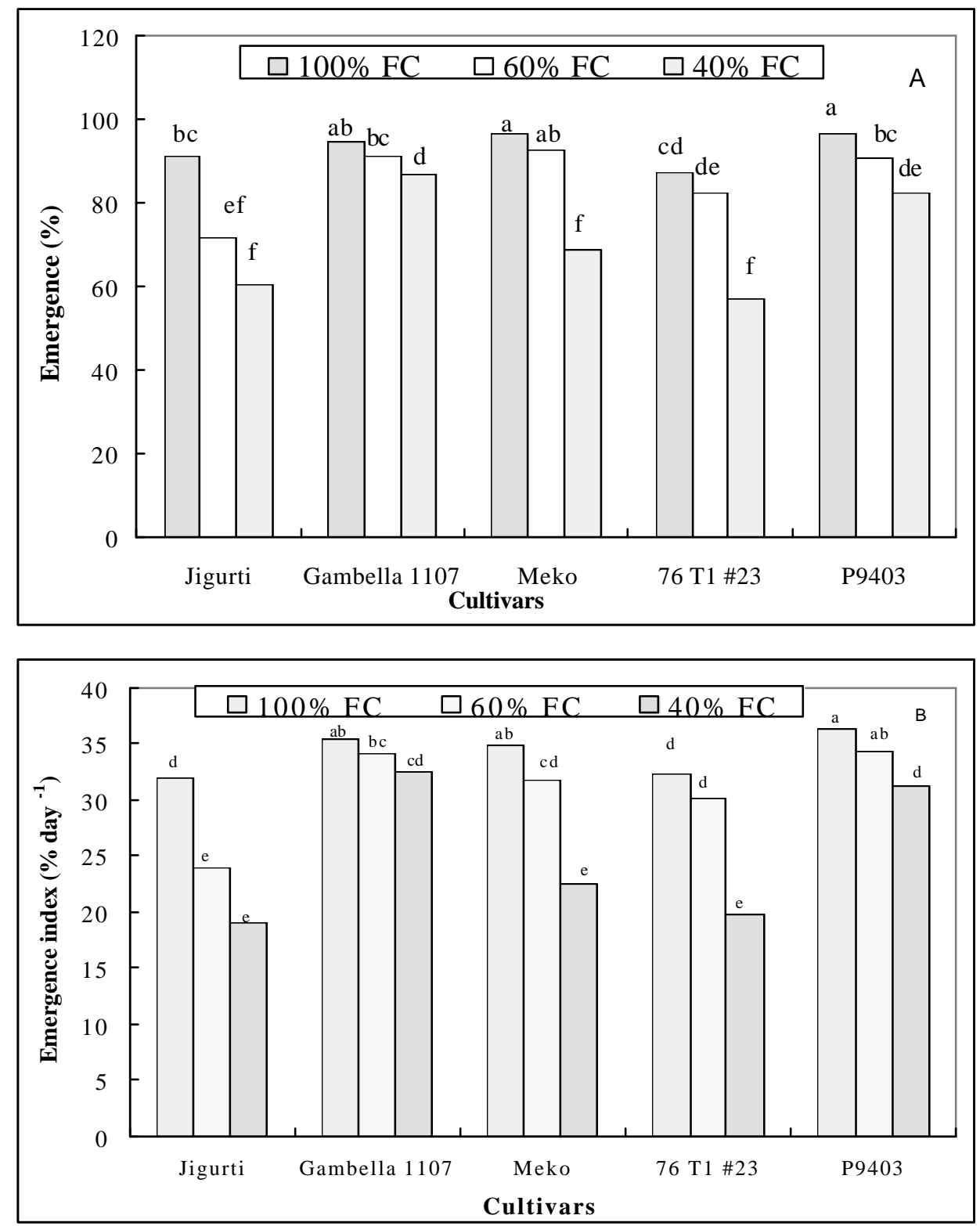

Figs 5 a and $\mathrm{b}$ Effect of growing media water content on final seedling emergence (A) and emergence index (B). Bars followed by the same letters are not significantly different at $\mathrm{P} \leq 0.05$. 


\section{Seedling shoot and root length and root area}

Seedling shoot length was significantly $(\mathrm{P}<0.01)$ affected by the interaction effects of growing media water content and cultivars (Fig. 6). In all the cultivars, shoot length was significantly $(\mathrm{P}<0.01)$ reduced with decreasing growing media water content. Shoot length was reduced by 14 and 27\% for Jigurti, 24 and 38\% for Gambella 1107, 19 and $42 \%$ for Meko, 18 and 35\% for 76 T1 \#23 and 21 and $40 \%$ for $\mathrm{P} 9403$ at 60 and $40 \%$ FC, respectively.

Root length was significantly $(\mathrm{P}<0.01)$ different between the growing media water content and cultivars interaction effects (Fig. 7a). The data indicated that reduction in growing media water content had adversely affected the root length of all cultivars, except in 76 T1 \#23 (Fig. 7a). Root length decreased by 41 and $51 \%$ for Jigurti, 34 and $41 \%$ for Gambella 1107, 30 and 36\% for Meko and 33 and $49 \%$ for P9403 under 60 and 40\% FC, respectively. Under no stress condition $(100 \%$ FC), Jigurti produced significantly longer roots, while the remaining cultivars had comparable root lengths. At lower growing media water content (60 and
$40 \%$ FC) both Jigurti and 76 T1 \#23 developed significantly longer roots compared to the other cultivars. Root length in 76 T1 \#23 was even promoted by increasing water deficit stress, which is probably an adaptive reaction. Gawronska and Grzelak (1993) reported similar observation in triticale, where root growth under water stress was increased compared to well watered plants. According to M'Ragwa et al. (1995), cultivars that can establish long extensive seedling root systems may have better seedling establishment as their root systems are able to rapidly penetrate the upper soil layers and continue water uptake, thus avoiding water deficit stress. Thus, selection for a vigorous and deep penetrating root system on the basis of root length could be an easy method of selecting for drought resistance. The results indicate that Jigurti and 76 T1 \#23 could have better seedling establishment at lower growing media water content as they can develop better root systems.

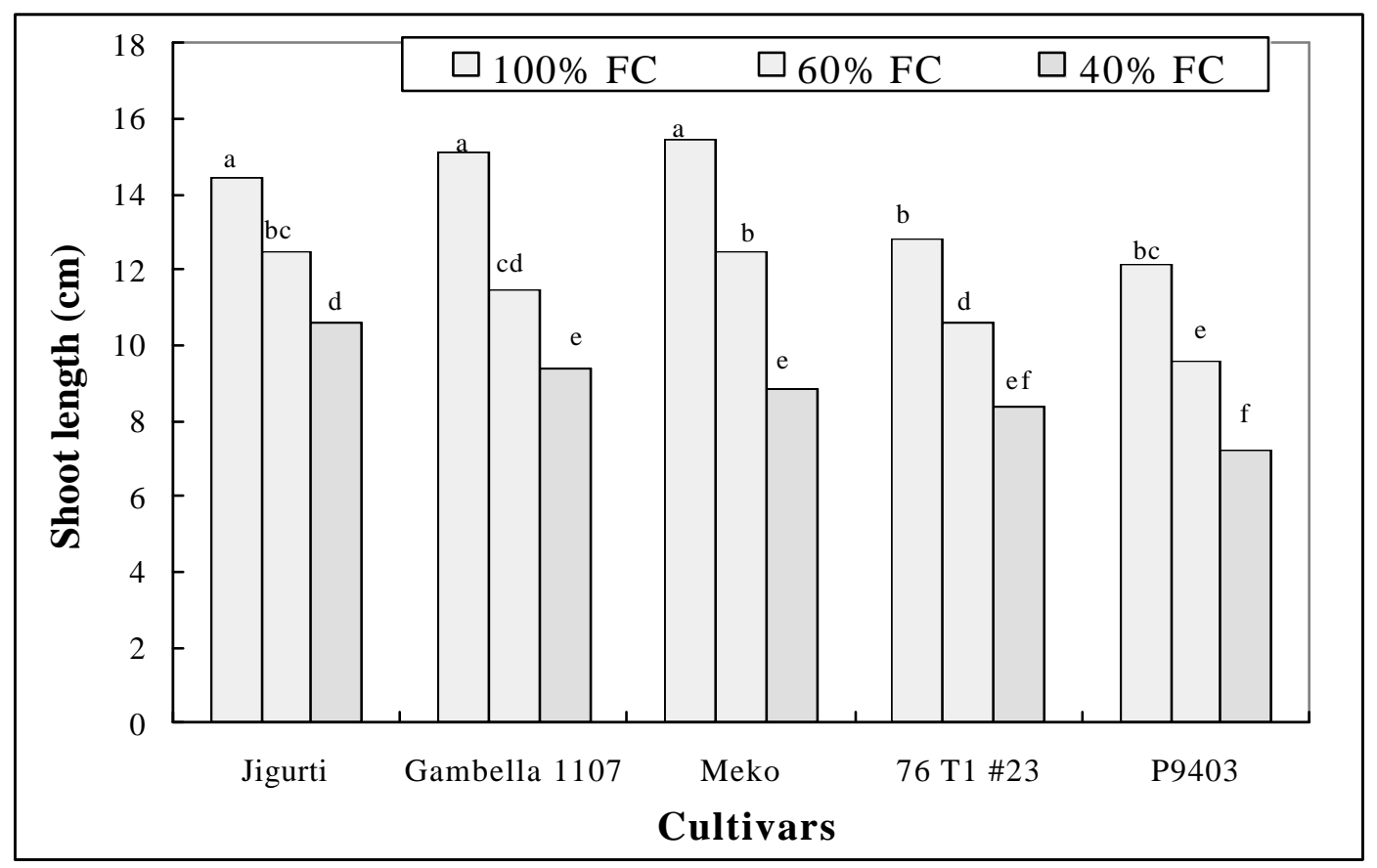

Fig. 6. Effect of growing media water content on shoot length. Bars followed by the same letters are not significantly different at $\mathrm{P} \ 0.05$. 
Differences in root area were observed between the interaction effects of growing media water content and cultivars. In all cultivars, except in 76 $\mathrm{T} 1$ \#23, root area declined significantly $(\mathrm{P}<0.01)$ as growing media water content decreases. While in 76 T1 \#23 root area increased with decreasing levels of growing media water content (Fig. 7b). Relative to the respective well watered plants, root area under 60 and $40 \%$ FC was reduced by 37 and $50 \%$ in Jigurti, by 33 and 48\% in Gambella 1107, by 32 and 57\% in Meko and by 25 and 53\% in P9403, respectively.
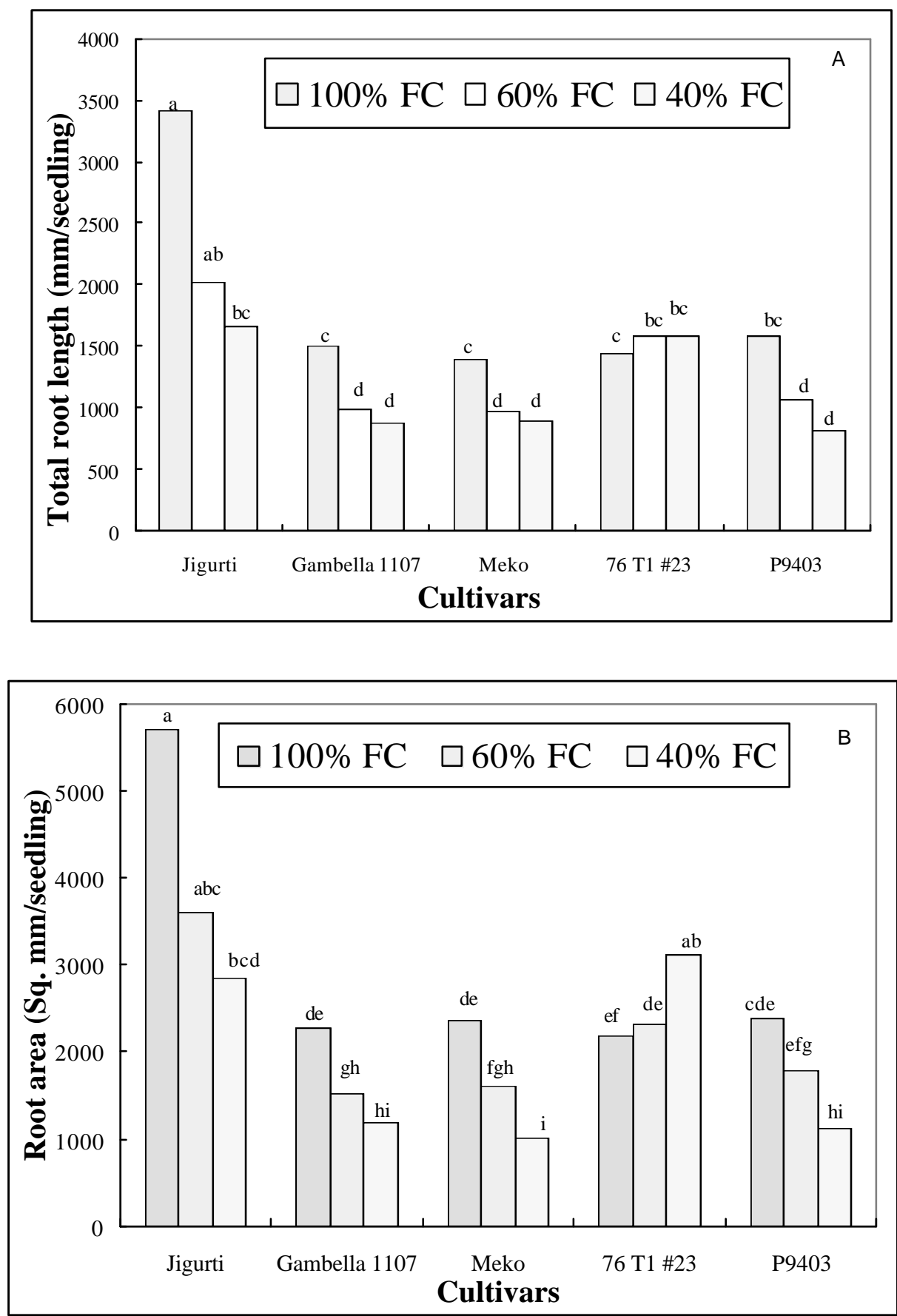

Figs 7a and b. Effect of growing media water content on total root length (A) and area (B) of sorghum cultivars. Bars followed by the same letters are not significantly different at $\mathrm{P} \ 0.05$. 


\section{CONCLUSION}

In both experiments increasing water deficit stress reduced the rate and percentage of germination and emergence, as well as the early growth of seedlings as indicated by coleoptiles, mesocotyls and radicle elongation and seedling shoot and root length and root area.

The speed of germination and emergence, the growth of the coleoptile, mesocotyl, and radicle and the shoot and root length and root area were found important traits to identify cultivars tolerant to water deficit stress at germination.

The presence of cultivar differences in water deficit tolerance at germination was demonstrated in these studies. Gambella 1107, Meko, and P9403 were found to be tolerant to water deficit stress as they had a significantly higher rate and percentage of germination and emergence. They required less time to reach final germination. Moreover, Gambella 1107 developed significantly longer coleoptiles, mesocotyls and radicles, which are important attributes for better emergence under water deficit stress. In terms of shoot length and root system development, Jigurti and Meko performed better. Jigurti and 76 T1 \#23 developed a longer root system with a larger root area, which are important attributes for early establishment under water stress condition. Results of these studies suggest that there is potential to select for water deficit stress tolerance within the Ethiopian sorghum gene pool. Thus, the results are very useful for breeders for future development of drought tolerant cultivars and for agronomists to predict sowing rates depending upon expected soil moisture conditions.

\section{REFERENCES}

1. Baalbaki, R.Z., Zurayk, R.A., Bleik, M.M. and Talhouk, N.S. (1999). Germination and seedling development of drought tolerant and susceptible wheat under moisture stress. Seed Sci. Technol. 27:291-302.
2. Belay, S. and Baker, D.B. (1996). An evaluation of drought screening techniques for Eragrostis tef. Trop. Sci. 36:74-85.

3. Brar, G.S. and Stewart, B.A. (1994). Germination under controlled temperature and field emergence of 13 sorghum cultivars. Crop Sci.34:1336-1340.

4. Brar, G.S., Steiner, J.L., Unger, P.W. and Prihar, S.S. (1992). Modeling sorghum seedling establishment from soil wetness and temperature of drying seed zones. Agron. J. 84:905-910.

5. Brigg, K.G. and Aytenfisu, A. (1979). The effect of seeding rate, seeding date and location on grain yield, maturity, protein percentage and protein yield of some spring wheat in central Alberta. Can. J. Plant Sci. 59:1129-1146.

6. Emmerich, W.E. and Hardegree, S.P. (1990). Polyethylene glycol solution contact effects on seed germination. Agron. J. 82:1103-1107.

7. Falleri, E. (1994). Effect of water stress on germination in six provenances of Pinus pinaster Ait. Seed Sci. Technol. 22:591-599.

8. Gardner, F.P., Pearce, R.B. and Mitchell, R.L. (1985). Physiology of crop plants. Iowa State University press, USA.

9. Gawronska, H. and Grzelak, K. (1993). Seed germination and seedling vigour of triticale $(X$ Triticosecale wittmack) under drought stress. Plant var. seeds 6:9-19.

10. Gurmu, M. and Naylor, RE.L. (1991). Effect of low water availability on germination of two sorghum cultivars. Seed Sci. Technol. 19:373-383.

11. Hunter, J.R. and Erickson, A.E. (1952). Relation of seed germination to soil moisture tension. Agron. J. 44:107-109.

12. Lafond, G.P. and Baker, R.J. (1986). Effects of temperature, moisture stress, and seed size on germination of nine spring wheat cultivars. Crop Sci. 26:563-567.

13. M'Ragwa, L.R.F., Watson, J.R. and Gourley, L.M. (1995). Selection response for seedling root length and coleoptile length in pearl millet. Crop Sci. 5:1032-1036.

14. Takahashi, N. (1978). Adaptive importance of mesocotyl and coloeptile growth in rice under different moisture regimes. Aust. J. Plant Physiol. 5:511-17.

15. Wanjari, K.B. and Bhoyar, M.P. (1980). Coleoptile length in sorghum. Seed Sci. Technol. 8:169-174. 